\title{
Obituary: Lewis Braverman
}

\author{
Fereidoun Azizi ${ }^{1, *}$ \\ ${ }^{1}$ Endocrine Research Center, Research Institute for Endocrine Sciences, Shahid Beheshti University of Medical Sciences, Tehran, Iran \\ "Corresponding author: Endocrine Research Center, Research Institute for Endocrine Sciences, Shahid Beheshti University of Medical Sciences, Tehran, Iran. Email: \\ azizi@endocrine.ac.ir
}

Received 2019 June 16; Accepted 2019 June 22.

Professor Lewis E Braverman, member of the editorial board of the International Journal of Endocrinology and Metabolism, deceased June 10, 2019, at the age of 89 years.

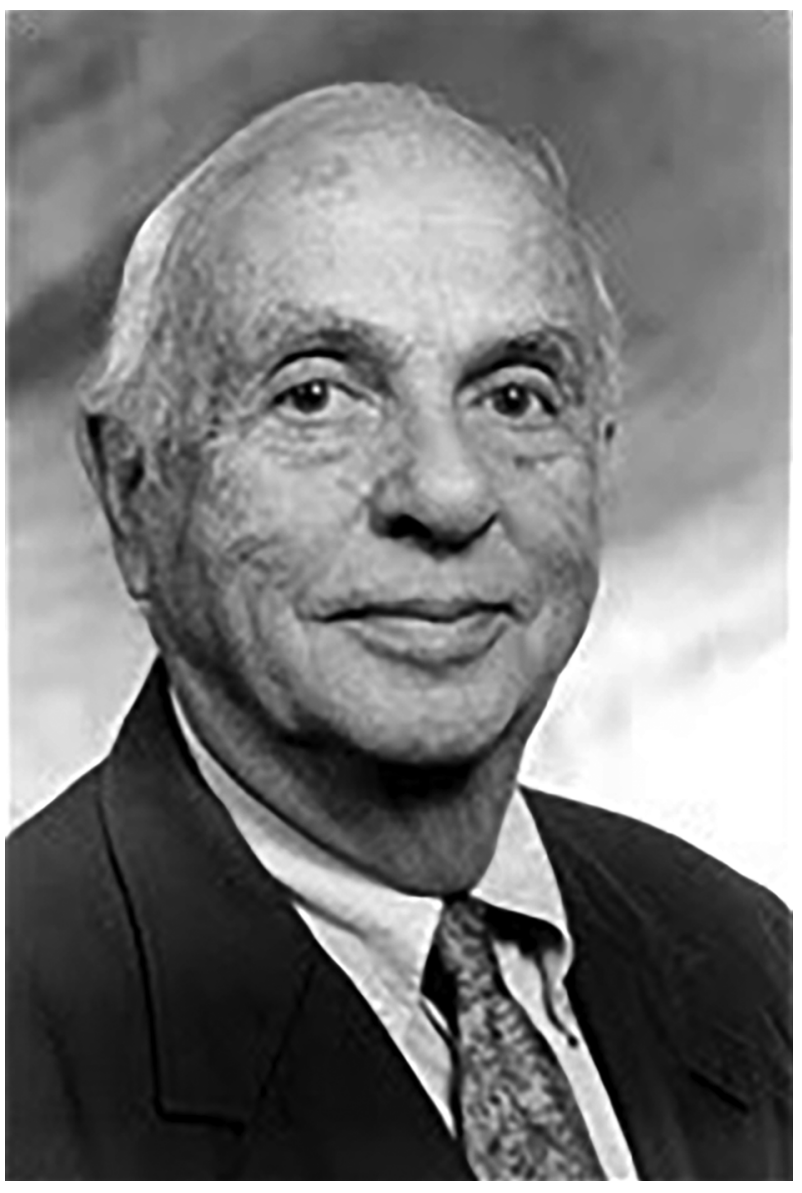

Figure 1. Professor Lewis E Braverman

He graduated from medical school at Johns Hopkins University in 1955, followed by an Internal Medicine Residency at Boston City Hospital and an Endocrinology Fel- lowship under the direction of Sidney H. Ingbar, MD in the Thorndike Memorial Laboratory. He was a thyroid clinician for a long time, loved by his patients and extended his warmth and kindness to all those at work, clinics, and hospitals.

Professor Braverman was a leading thyroid researcher with $>600$ manuscripts. His seminal demonstration that T4 was converted to T3 in humans was published in 1970. He also identified familial dysalbuminemic hyperthyroxinemia in 1982 and discovered the etiology of an outbreak of thyrotoxicosis in the Midwest due to the inclusion of the bovine thyroid gland in the manufacturing of hamburger in 1987. He was also an international expert in iodine metabolism. He was longtime co-editor of the leading thyroid textbook, The Thyroid: A Fundamental and Clinical Text.

Professor Braverman served as the American Thyroid Association (ATA) president in 1985. He was the recipient of virtually all the ATA awards: The Van Meter Award (1963), the Distinguished Service Award (1987), the Paul Starr Award (1988), the Ingbar Award (1990) and the Stanbury Award (2003).

Professor Braverman is remembered as a superb mentor to generations of endocrine trainees. In 2011, the ATA established the Lewis E. Braverman Distinguished Award Lectureship, which recognizes an individual who has demonstrated the excellence and passion for mentoring fellows, students, and junior faculty. He was truly one of the giants in endocrinology.

The endocrine community and the International Journal of Endocrinology and Metabolism have lost in Lewis Braverman an outstanding member. 